\title{
INCREASED FORMATION OF PREGANGLIONIC SYNAPSES AND AXONS DUE TO A RETROGRADE TRANS-SYNAPTIC ACTION OF NERVE GROWTH FACTOR IN THE RAT SYMPATHETIC NERVOUS SYSTEM $^{1}$
}

\author{
T. SCHÄFER, ${ }^{2}$ M. E. SCHWAB, ${ }^{3}$ AND H. THOENEN \\ Max Planck Institute for Psychiatry, Department of Neurochemistry, 8033 Martinsried, Federal Republic of Germany
}

Received June 14, 1982; Revised January 31, 1983; Accepted January 31, 1983

\begin{abstract}
The role which postsynaptic target cells play in the development of their presynaptic innervation has been studied in the superior cervical ganglion (SCG) of the rat using nerve growth factor (NGF), which selectively acts on the postganglionic sympathetic neurons. In neonatal rats, daily injections of $10 \mu \mathrm{g}$ of NGF/gm of body weight for 10 days caused in the SCG the typical increase in neuronal size and an enhanced differentiation of the ganglionic neurons, as reflected by a 5 -fold higher protein content and by a 3.7-fold higher specific activity of tyrosine hydroxylase.

However, the NGF treatment also had indirect retrograde trans-synaptic effects, so that by 5 to 10 days the number of presynaptic terminals in the SCG was double that in the ganglia of control animals of the same age, and after 10 days the level of choline acetyltransferase in the ganglion was increased by $60 \%$. The enhanced formation of synapses was accompanied by an increased number of axons in the preganglionic nerve: after 10 days of NGF treatment the number of cholinergic axons in the cervical sympathetic trunk was increased from about 6,000 to 20,000 axons.

This result points to a stabilization of otherwise transitory projections and/or an induction of additional branching of the preganglionic fibers, produced by the NGF-mediated alterations of the target structure (the SCG). Increased survival of young preganglionic cell bodies, i.e., prevention of naturally occurring cell death, could further contribute to the observed increase in axon and synapse numbers. A direct NGF-mediated sprouting was also seen for the few adrenergic neurons in the SCG and stellate ganglion, projecting into the preganglionic nerve.
\end{abstract}

During development, many types of neurons are dependent for their survival and differentiation on the availability of appropriate target cells (Black, 1978; Landmesser and Pilar, 1978; Thoenen et al., 1979; Landmesser, 1980; Grinnell and Herrera, 1981). This has been shown mainly by studying the effects of target organ removal. In the peripheral sympathetic nervous system, destruction of the postganglionic neurons by 6-hydroxydopamine, axotomy, or anti-nerve growth factor (NGF) antiserum in neonatal rats leads to a corresponding decrease in the number of preganglionic axons (Aguayo et al.,

\footnotetext{
${ }^{1}$ We wish to thank Dr. J. Thibault, of Paris, for his gift of tyrosine hydroxylase antiserum, Dr. G. Harper for critical reading of the manuscript, and Mrs. E. Eichler for typing the manuscript. This work was supported by the Swiss National Foundation (Grant 3.432.74).

${ }^{2}$ Present address: Department of Biochemistry, Biocenter, University of Basel, Basel, Switzerland.

${ }^{3}$ To whom correspondence should be addressed at Max Planck Institute for Psychiatry, Department of Neurochemistry, Am Klopferspitz 18 a, D-8033 Martinsried (Munich), FRG.
}

1976) and cell bodies in the spinal cord (Johnson et al., 1977), and to a failure of the normal increase in choline acetyltransferase (CAT) (Black et al., 1972). In adult guinea pigs and rats, synaptic disconnection occurs in the superior cervical ganglion (SCG) as a consequence of postganglionic axotomy or blockade of axonal transport (Purves, 1975, 1976; Matthews and Nelson, 1975). Interestingly, the event leading to this detachment and retraction of the presynaptic terminals are counteracted by NGF and mimicked by anti-NGF antiserum ( $\mathrm{Njå} \mathrm{and}$ Purves, 1978).

In the normal neonatal rat, NGF enhances the maturation and general growth of postganglionic neurons (for review, see Thoenen and Barde, 1980), and hence it is possible to study the effects of these altered postsynaptic conditions on the development of the innervating preganglionic neurons. In particular, NGF causes an increase in the general protein synthesis and an enlargement of the SCG neurons with a subsequent increase in the cell division of Schwann and satellite cells and specific increases in the levels of the enzymes involved in the 
synthesis of norepinephrine (tyrosine hydroxylase (TH) and dopamine $\beta$-hydroxylase). In addition, the observation of an increase of CAT over the normally occurring developmental increase again indicates a retrograde transneuronal effect of the NGF treatment (Thoenen et al., 1972).

In the present morphological study we show pronounced transneuronal effects on the preganglionic innervation of the SCG due to the NGF-induced changes in the postganglionic neurons: thus, synapse formation is enhanced and the number of preganglionic axons innervating the SCG is increased.

\section{Materials and Methods}

NGF was isolated from the submandibular glands of adult male mice according to the method of Bocchini and Angeletti (1969), as modified by Suda et al. (1978). The biological activity of the preparation was about 200 biological units/ $\mu$ g of NGF.

Newborn (designated day 0) Sprague-Dawley rats of either sex were subcutaneously injected daily with $10 \mu \mathrm{g}$ of NGF/gm of body weight for 2, 5, or 10 days. Control animals received saline.

Enzyme assays. At day 0, 2, 5, or 10, animals from experimental and control groups were killed by exposure to ether, and their SCGs were removed with the aid of a dissecting microscope. The ganglia from each rat were pooled and homogenized at $4^{\circ} \mathrm{C}$ in $500 \mu \mathrm{l}$ of $0.05 \mathrm{M}$ Tris$\mathrm{HCl}$ buffer $(\mathrm{pH} \mathrm{7.4)}$ containing $0.1 \%(\mathrm{v} / \mathrm{v})$ Triton X-100.

$\mathrm{TH}$ activity was determined according to the method of Levitt et al. (1967) as modified by Mueller et al. (1969). CAT activity was assayed according to the method of Fonnum (1975). Enzyme activities were linear with time and with the amount of enzyme protein. Protein concentrations were determined according to the method of Lowry et al. (1951) using bovine serum albumin (BSA) as the standard.

Histological procedures. At day 0, 2, 5, or 10, animals from experimental or control groups were anesthetized with ether and perfused through the heart, first with a short pre-rinse of Ringer solution containing 1000 units of heparin (Liquemine, Hoffmann-La Roche, Basel, Switzerland) and $0.1 \%$ procaine, and then for $15 \mathrm{~min}$ with a mixture of $2.5 \%$ glutaraldehyde and $1 \%$ paraformaldehyde in $0.1 \mathrm{M}$ phosphate buffer $(\mathrm{pH} 7.4)$ containing $5 \%$ $(\mathrm{w} / \mathrm{v})$ sucrose. Control animals were also studied at day 50 . The number of animals killed at each time point was 4 to 8 per group.

Both SCGs and both cervical sympathetic trunks (CSTs) were carefully removed with the aid of a dissecting microscope and were immersed together in the same fixative for an additional $2 \mathrm{hr}$. The specimens were separated into ganglia and CSTs postfixed in $\mathrm{OsO}_{4}$, dehydrated, and embedded in Epon 812. Ultrathin sections were cut on a Reichert Ultratome and mounted on copper one-hole grids supplied with carbon-Pioloform films (Pioloform F, Wacker Chemie, Munich, FRG). After staining with uranyl acetate and lead citrate, the sections were examined in a Zeiss EM 10 electron microscope.

For the determination of the number of intrinsic synapses in the SCG of control and NGF-treated rats, four animals from each group were anesthetized with ether at day 10 , and the right SCG was decentralized by cutting the CST 2 to $3 \mathrm{~mm}$ from the ganglion. Five days after the decentralization, the animals were perfused and the SCGs were processed as described above.

Morphometry. For the determination of synapse density, sections were cut from the midportions of the ganglia perpendicular to their long axis. Synapses were counted from electron micrographs covering an area of about $10,000 \mu \mathrm{m}^{2}$ and printed at a final magnification of $\times$ 13,000 . Only synapses with clearly visible asymmetric pre- and postsynaptic membrane thickenings and with presynaptic vesicles were counted (Fig. 4). Nerve cell nuclei and Schwann cell nuclei were counted on the same sections, but from overlapping electron micrographs covering an area of about $25,000 \mu \mathrm{m}^{2}$, and printed at a final magnification of $\times 4,100$.

The numbers, per unit area of synapses, of nerve cell nuclei and of Schwann cell nuclei were calculated, and hence the number of synapses per nerve cell nucleus and the number of Schwann cell nuclei per nerve cell nucleus were determined. This approach was found to give the most reliable results, although the increase in synapse numbers under the influence of NGF is underestimated by such determination, because the number of neurons is more than $20 \%$ higher in NGF-treated animals (Hendry and Campbell, 1976). Ganglionic volume, neuronal volume, and ganglionic extracellular space were all changed markedly by NGF treatment.

For the determination of the number of axons in the CST, ultrathin sections were cut perpendicularly to the CST at two different levels: near its entry into the SCG and about $3 \mathrm{~mm}$ centrally toward the spinal cord. The axon number was calculated by first determining the axon density in randomly chosen regions of the CST that were photographed and printed at a final magnification of $\times 16,000$; from this density the total number of axons was then obtained by extrapolating the total area of CST composed by axons, as determined with a Hewlett-Packard 9874A digitizing device from whole cross-section montages printed at a final magnification of $\times 4,100$.

At each time point, the differences between the values in NGF-treated animals and in controls were tested for statistical significance using the Student's $t$ test.

Immunohistochemical procedure. For the determination of the number of adrenergic axons in the CST, 10day-old NGF-treated and untreated rats were perfused through the heart with $4 \%$ formalin in $0.1 \mathrm{~m}$ phosphate buffer, $\mathrm{pH} 7.4$, for $5 \mathrm{~min}$, then with $4 \%$ formalin in $0.1 \mathrm{M}$ borate buffer, $\mathrm{pH} 11$, for $10 \mathrm{~min}$. The SCG with CST and postganglionic trunks were removed and immersed for an addition hour in the second fixative (Berod et al., 1981). After washing in $0.1 \mathrm{~m}$ phosphate buffer, $\mathrm{pH} 7.4$, containing $5 \%$ sucrose, the tissue was embedded in polyethylene glycol 600 (Fluka, Buchs, Switzerland). Blocks were hardened and stored at $4^{\circ} \mathrm{C}$, and $15-\mu \mathrm{m}$ sections were cut parallel to the long axis of the trunks. The following incubation steps were carried out at room temperature in $0.1 \mathrm{M}$ phosphate buffer, $\mathrm{pH} 7.4$, containing $5 \%$ sucrose, $5 \%$ BSA, and $0.2 \%$ Triton X-100. Anti-TH antiserum or rabbit nonimmune serum was diluted 1:500 (gift from Dr. J. Thibault, Paris) and incubated over- 
$1 a$

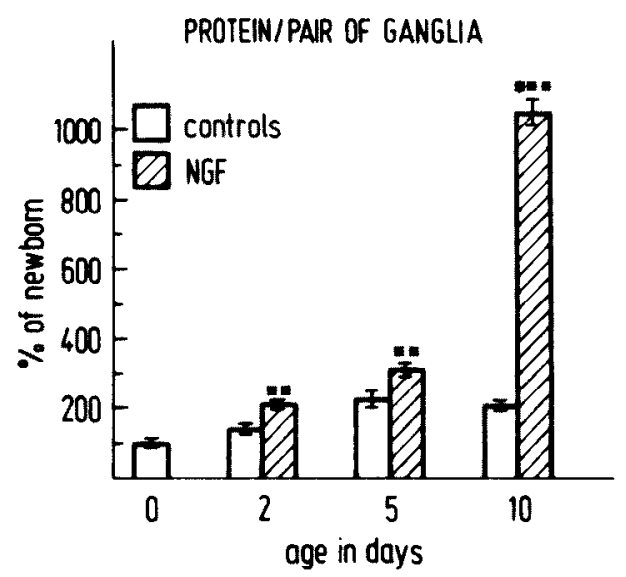

16

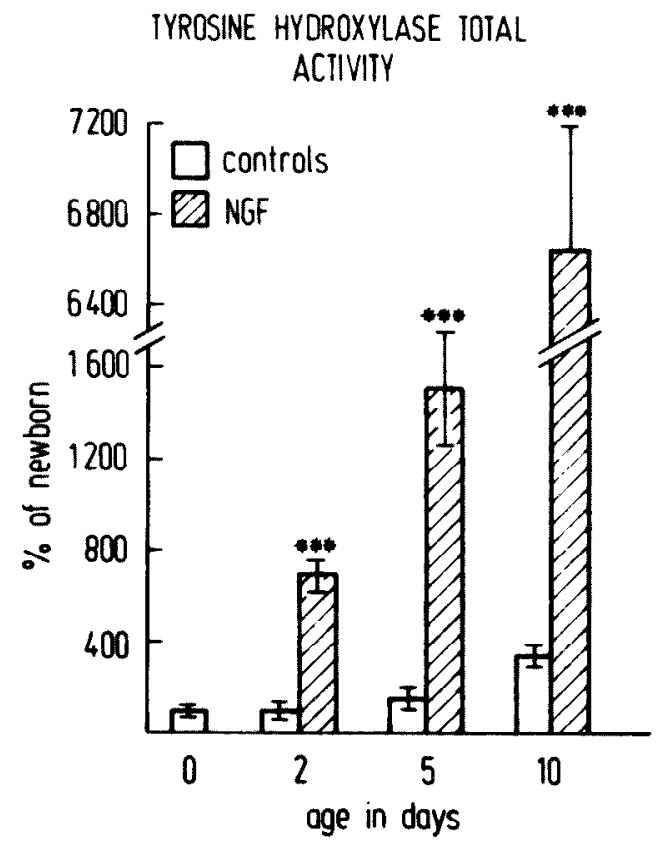

1c

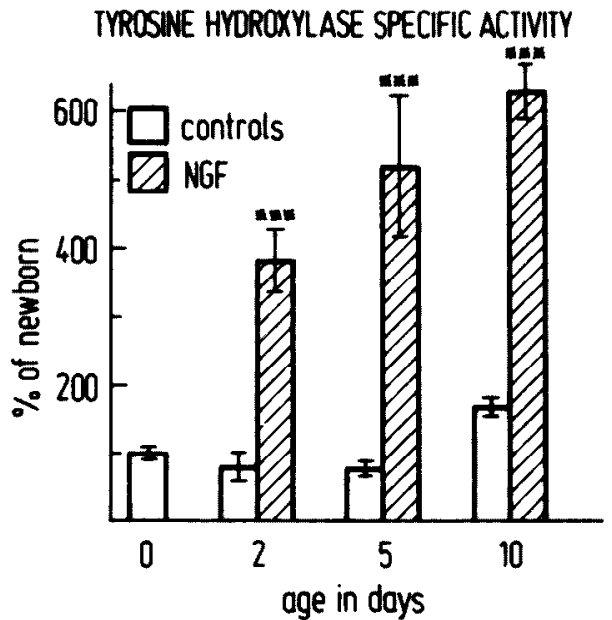

Figure 1. Developmental increases in (a) protein content, (b) $\mathrm{TH}$ total activity, and (c) TH specific activity in rat SCGs under the influence of NGF. Animals were injected daily, subcutaneously, with $10 \mu \mathrm{g}$ of $\mathrm{NGF} / \mathrm{gm}$ of body weight or with saline for 2,5 , or 10 days. Results are expressed as percentage (mean \pm SEM) of the values for newborn animals: $100 \%=113$ night. The antiserum was raised against $\mathrm{TH}$ purified from rat pheochromocytoma tumors (Thibault et al., 1981). After washing for $2 \mathrm{hr}$, sections were incubated in peroxidase-coupled anti-rabbit IgG antibodies (MilesYeda, Rehovot, Israel) that were diluted 1:100 and were reacted using diaminobenzidine (Sigma Chemical Co., St. Louis, MO) as a substrate, and a heavy metal intensification (Adams, 1981). Sections were treated with osmium and embedded in Epon 812. Ultrathin sections were cut perpendicularly to the $15-\mu \mathrm{m}$ section to give cross-sections through the axons in the trunks. The proportion of labeled, adrenergic axons was determined on micrographs printed at a final magnification of $\times 12,000$.

Retrograde labeling with horseradisch peroxidase (HRP). HRP was applied to the right CST of 10-day-old NGF- or saline-treated rats by placing the cut ends of the CST into a polyethylene tube containing $30 \%(\mathrm{v} / \mathrm{v})$ HRP, type VI (Sigma) in a $15 \%$ polyacrylamide gel (Griffin et al., 1979). In addition, a dry pellet of crystalline enzyme was put on top of the tubing. The total quantity of HRP applied was about $1 \mathrm{mg}$. After $40 \mathrm{hr}$, the animals were perfused with $3 \%$ glutaraldehyde in $0.1 \mathrm{M}$ cacodylate buffer at $\mathrm{pH}$ 7.4. SCGs, stellate ganglia, CSTs, and cervical and thoracic spinal cord segments were removed and stored in the same buffer at $4^{\circ} \mathrm{C}$. Thirty-micrometerthick cross-sections of ganglia and spinal cord were cut on a freezing microtome at $-15^{\circ} \mathrm{C}$. Sections were reacted with tetramethyl benzidine according to the procedure of Mesulam (1978), counterstained with thionin (Adams, 1980 ), and examined in a Leitz microscope using polarizing filters.

For control experiments, 10-day-old animals either received a tail vein injection of $1 \mathrm{mg}$ of HRP in saline or were sham-operated with the application of 1 or $5 \mathrm{mg}$ of HRP to the intact CST, and processed as described above.

\section{Results}

\section{Effects of NGF on postganglionic neurons in the SCG}

In control animals, the total protein content of the SCG increased 2-fold from birth (day 0 ) to day 10; NGF treatment resulted in a 10 -fold increase in total protein content (Fig. 1a). This increase was in sharp contrast to the rise in body weight: NGF-treated animals consistently showed a slower than normal increase in body weight ( $87 \%$ of control values at day $2,75 \%$ at day 5 , and $77 \%$ at day 10 ).

In control animals, tyrosine hydroxylase total activity increased 3.4-fold and the specific activity increased 1.7fold during the first 10 days of postnatal development (Fig. 1, $b$ and $c$ ). NGF treatment led to a 66 -fold rise in TH total activity, causing a 6.3 -fold increase in the specific activity of TH (Fig. 1, b and $c$ ). This is in good agreement with earlier results (Thoenen et al., 1971).

Morphological observations. At birth, most of the SCG neurons were still typical young neurons having a

$\mu \mathrm{g}$ of protein/puir of ganglia; $1.0 \mathrm{pmol}$ of dihydroxyphenylalanine (DOPA) formed/min/pair of ganglia ( $\mathrm{TH}$ total activity), and $9 \mathrm{pmol}$ of DOPA formed $/ \mathrm{min} / \mathrm{mg}$ of protein (TH specific activity); $n=8$ animals. $* *, p<0.01 ; * * *, p<0.001$. 
large nucleus and a relatively small rim of cytoplasm (Fig. 2a), as described by Eränkö (1972). Non-neuronal cells were small, covering only minor portions of the nerve cell bodies and fibers. The size of the nerve cell bodies was markedly increased from birth to day 10 (Fig. $2 b$ ), and non-neuronal cells increased in number (Fig. $4 b$ ) and began to ensheath the neurons and their fibers. All of these processes were markedly enhanced by NGF.

After 10 days, the diameters of neurons in NGF-treated ganglia were nearly double those of neurons in 10-dayold controls, and the neurons in NGF-treated animals were totally surrounded by Schwann cells (Fig. 2c).

\section{Development of the preganglionic SCG innervation and its modification of NGF}

Choline acetyltransferase showed a 14-fold increase in total activity during the first 10 days postnatally in controls (Fig. 3). NGF treatment during these 10 days caused a further increase by about $60 \%$. However, after 2 or 5 days of NGF treatment, the total CAT activity was significantly lower than in controls $(77 \%$ at 2 days and $68 \%$ at 5 days).

In the electron microscope only few distinct synapses were found at the day of birth. Their morphology closely resembled that of classical ganglionic cholinergic synapses: asymmetric thickenings, clear $50-\mathrm{nm}$ vesicles, and occasional large dense-core vesicles. The number of synaptic vesicles was, however, smaller at birth than at 10 days or in adult animals. Both axosomatic and axodendritic synapses were present. No "vacant" postsynaptic thickenings (Smolen and Raisman, 1980) could be observed in the ganglia of either NGF-treated or control animals.

For a quantitative assessment of synapse formation, synapses were counted in a given field and their number was related to that of nerve cell nuclei in the same field of observation (see Morphometry under "Materials and Methods"). In the controls, the developmental increase in synapse numbers determined by this procedure corresponded closely to that reported by Smolen and Raisman (1980) for the total number of synapses per SCG. In saline-injected animals, there was a steady rise from 0.4 synapses/nerve cell nucleus at birth to 1.3 synapses/ nerve cell nucleus at 10 days (Fig. $4 a$ ). NGF produced an additional 1.5-fold increase in synapse numbers over control values by day 2 , and a 2 -fold increase by days 5 and 10 (Fig. $4 a$ ).

As the surface area of a peripheral neuron covered by one Schwann cell has been reported to be constant (Pannese et al., 1972), the relative neuronal surface area present in the SCG was estimated by determining the number of Schwann cell nuclei per nerve cell nucleus in a given field of observation. For control and NGF-treated animals, the increase in the number of Schwann cell nuclei per nerve cell nucleus was similar to the corresponding increase in the number of synapses (Fig. 4, $a$ and $b$ ), indicating that the formation of synapses in the SCG is roughly proportional to the increase in the neuronal surface area.

The true preganglionic nature of these synapses was established by decentralization of the SCG after 10 days of NGF or saline treatment. Five days after decentrali- zation, the number of synapses remaining in the ganglion was only $7 \%$ in NGF-treated animals and $10 \%$ in salinetreated animals as compared to nonoperated control animals.

The total number of axons in the preganglionic CST close to the SCG drops from 13,000 at birth to 7,700 at 10 days in control animals, confirming the earlier data of Aguayo et al. (1973). NGF (reatment not only prevented this loss, but even increased the number of axons above control levels as early as after 2 days of treatment $(21,000$ axons), and to a maximal number of 37,000 axons after 10 days of treatment (Figs. 5 and 6 ). This proliferation of axons was not restricted to the immediate vicinity of the target cells, as axon numbers in the CST were reduced by only 10 to $20 \%$ several millimeters closer to the spinal cord at all time points tested. This small difference was also observed in control animals.

Nature of CST axons. A substantial proportion of postganglionic axons (11\% in adult rats; Brooks-Fournier and Coggeshall, 1981) is present in the CST, and the corresponding adrenergic neurons in the SCG and the stellate ganglion (Bowers and Zigmond, 1979, 1981) can also be expected to sprout in response to NGF. Therefore, the nature of the axons in the CST had to be determined. Immunohistochemical experiments using an antiserum against $\mathrm{TH}$, an enzyme specifically located in adrenergic neurons, resulted in the staining of $20 \%$ of the axons in cross-sections through the CST of 10-day-old control animals. This proportion of TH-positive axons increased to $45 \%$ following NGF treatment (Fig. $7 a$ ). In crosssections through the postganglionic trunk, assumed to be purely adrenergic, more than $95 \%$ of all postganglionic axons were stained positively in both control and NGFtreated animals, confirming that $\mathrm{TH}$ immunoreactivity is a reliable marker for young adrenergic axons (Fig. $7 b$ ). In cross-sections through the CST that were treated with nonimmune serum, no labeled axons were found.

In a preliminary study using retrogradely transported HRP, the cells of origin of the CST axons were identified. In control animals, in agreement with the small proportion of TH-positive axons in the CST, only few adrenergic neurons were labeled in the SCG, which is similar to the adult situation in the rat (Bowers and Zigmond, 1979). Despite the increase in the number of adrenergic axons in the CST, this number was not affected by NGF treatment for 10 days. In addition, a minor number of stellate ganglionic neurons project axons into the CST (Bowers and Zigmond, 1981); but, again, this number was not increased in NGF-treated as compared to control animals in this study. In contrast to this constant number of labeled adrenergic neurons, the number of preganglionic sympathetic neurons labeled retrogradely in the spinal cord of treated animals seemed to be increased markedly (about 1.5-fold), although their rostrocaudal distribution along the spinal cord segments was the same as for control and adult animals. (segments C8 to T6; Rando et al., 1981; data not shown).

\section{Discussion}

The present results demonstrate that the effects of NGF in the neonatal rat are not restricted to the postganglionic sympathetic neurons, but extend also to the 

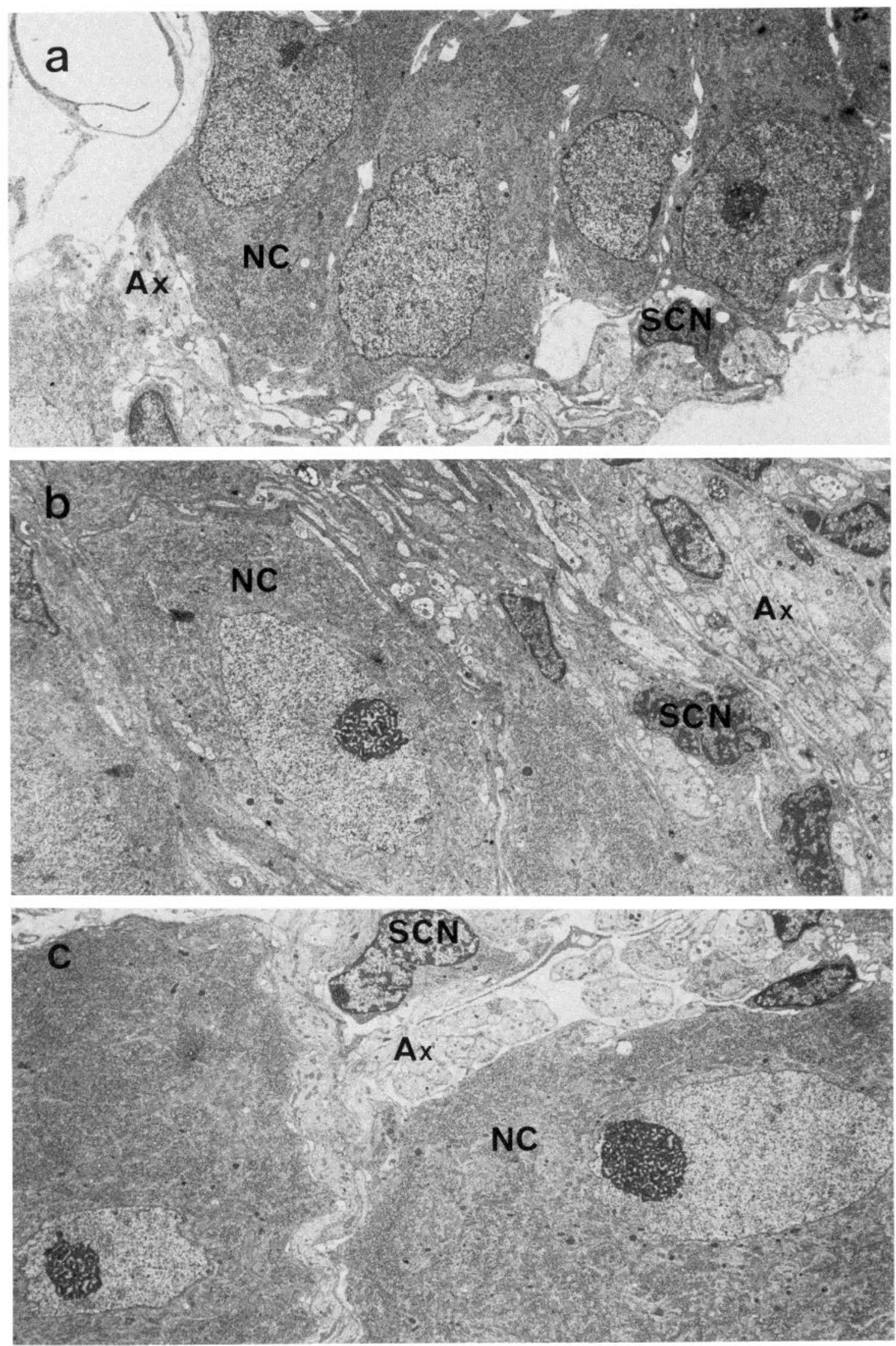

Figure 2. Electron micrographs of rat superior cervical ganglia (SCG). $a$, SCG of a newborn animal, showing typical neuroblasts with small rims of cytoplasm and relatively large nuclei. Cell membranes of neighboring cells are often seen in close contact. There are only few non-neuronal cells, which have mostly short processes. $b$, SCG of a 10-day-old control animal. Neurons are larger and are partially ensheathed by Schwann cell processes. $c$, SCG of a 10-day-old animal, injected with NGF. This treatment caused an enhanced growth of neurons, a prominent increase of the ratio of cytoplasmic area to nuclear area, and an increase in the number of Schwann cells, which totally ensheath the neurons and their processes. All micrographs are printed at a final magnification of $\times 3000$. NC, adrenergic neuron; $S C N$, Schwann cell nucleus; $A x$, axons. 


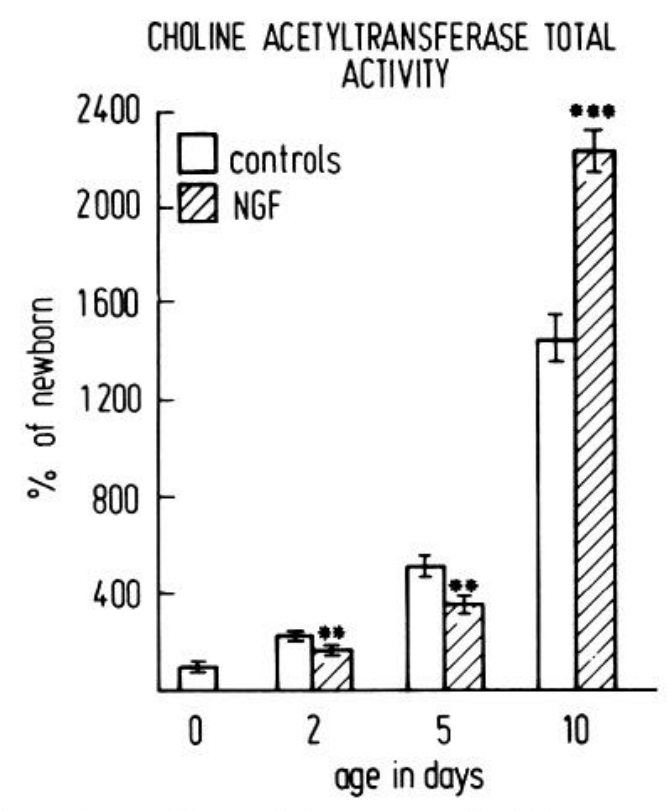

Figure 3. Developmental increase of choline acetyltransferase (CAT) total activity in rat CSGs under the influence of NGF. Animals were subcutaneously injected with $10 \mu \mathrm{g}$ of $\mathrm{NGF} / \mathrm{gm}$ of body weight or with saline for 2,5 , or 10 days. The results are expressed as percentage (mean \pm SEM) of the values for newborn animals: $100 \%=42 \mathrm{pmol}$ of acetylcholine formed/ $\mathrm{min} /$ pair of ganglia; $n=8$ animals. $* *, p<0.01 ; * * *, p<0.001$.

preganglionic innervation of these cells: there is a 2-fold increase in the number of synapses per neuron, a corresponding increase in CAT, and an increase in the number of preganglionic axons (about 3-fold) innervating the sympathetic ganglionic cells of the SCG.

The additional increase in synapse numbers and CAT content over the normal developmental increase substantiates earlier biochemical reports on such a retrograde transneuronal effect of NGF (Thoenen et al., 1972; Hill and Hendry, 1977). However, whereas in control rats there was a close correlation between synapse numbers and CAT levels at all ages (an observation reported also for mice, Black et al., 1971), at days 2 and 5 total CAT activity was significantly lower in NGF-treated animals as compared to controls. The time course of the increase in CAT synthesis in the spinal cord is not known, and it must be considered that CAT is transported from the spinal cord to the SCG over a distance of several millimeters by slow axonal transport (Saunders et al., 1973; Wooten and Coyle, 1973).

The preganglionic nature of these additional synapses was verified by cutting the preganglionic nerve. After 5 days, in both NGF-treated animals and controls, the number of synapses had dropped to $7 \%$ and $10 \%$, respectively. These residual synapses may represent intraganglionic connections by axonal collaterals (Kondo et al., 1980). The drop in the number of synapses correlates with the drop in CAT activity which falls to less than $10 \%$ of normal levels after decentralization (Thoenen et al., 1972; Hill and Hendry, 1977).

The increase in the number of synapses was paralleled by a hypertrophy of the postsynaptic SCG neurons and by a corresponding increase in the number of Schwann cells. Under the assumption that the surface area of a sympathetic neuron covered by one Schwann cell is constant, as has been reported for sensory neurons (Pannese et al., 1972), the increased formation of synapses in the SCG is roughly proportional to the increase in the neuronal surface area. Analogously, in ciliary ganglia, the number of axons making contacts with a given neuron correlates with the size of its dendritic tree (Purves and Hume, 1981). NGF reaches the SCG mainly
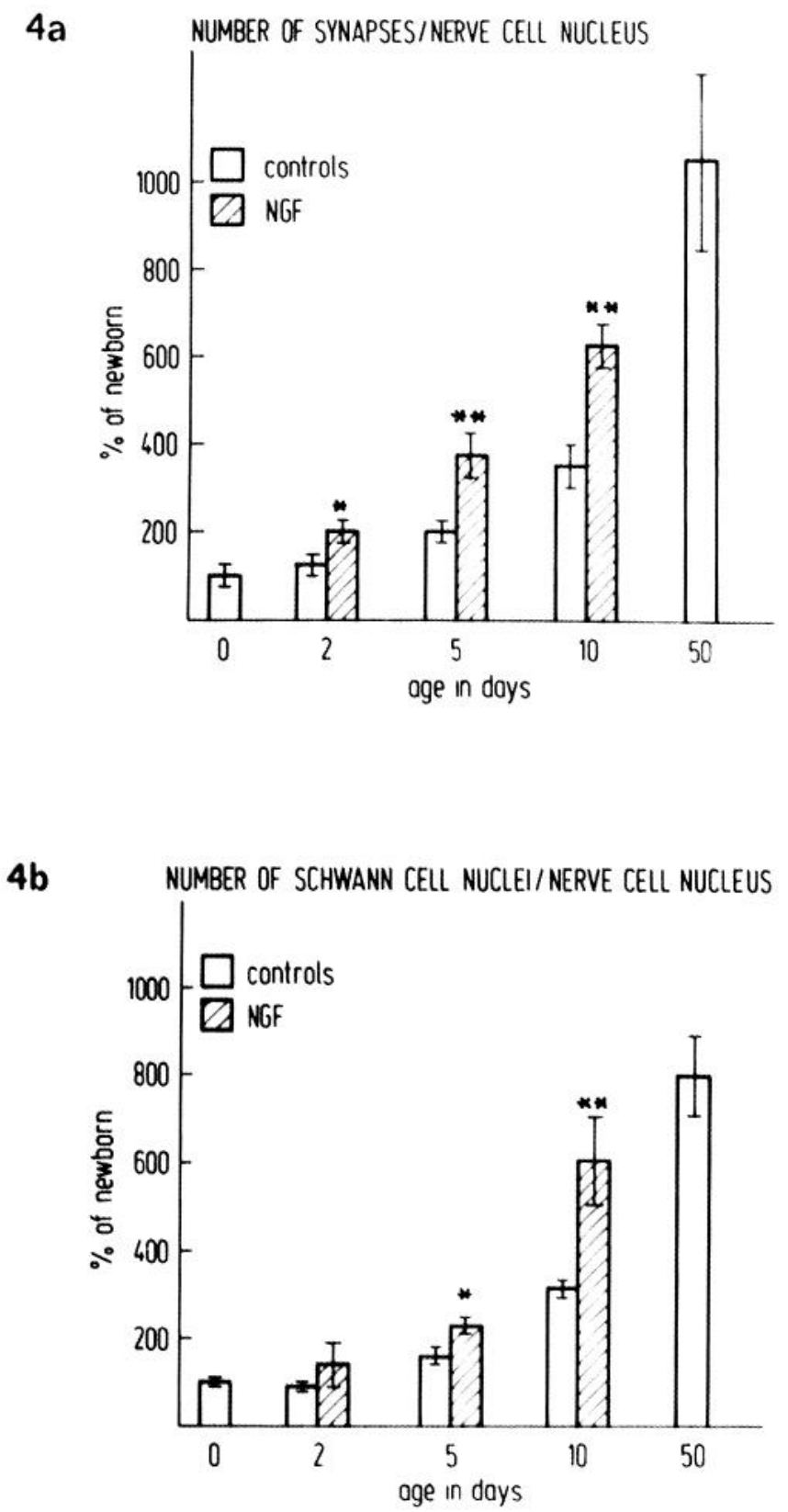

Figure 4. Time courses of the increase in $(a)$ the number of synapses and $(b)$ the number of Schwann cells per nerve cell nucleus in rat SCGs under the influence of NGF. The numbers of synapses, nerve cell nuclei, and Schwann cell nuclei were estimated as indicated under "Materials and Methods." The results are expressed as percentage (mean \pm SEM) of the values of newborn animals: $100 \%=0.41$ synapses/nerve cell nucleus and 1.0 Schwann cell nucleus/nerve cell nucleus; $n=6$ ganglia. $*, p<0.05 ; * *, p<0.01$. 


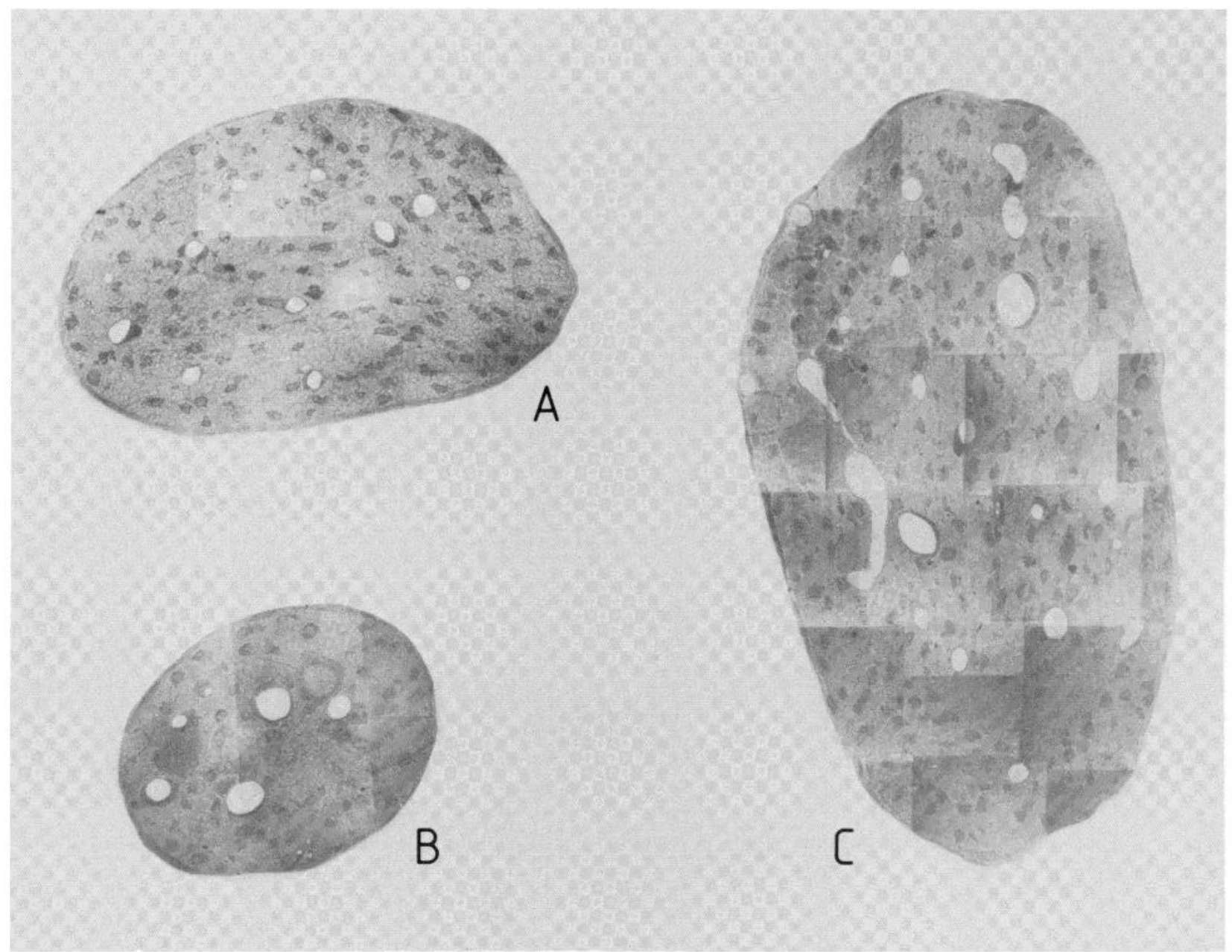

Figure 5. Montages of cross-section through the rat CST at its entry into the SCG. $A$, Newborn animal; $B$, 10 -day-old control animal; $C, 10$-day-old NGF-treated animal. Magnification $\times 80$. The numbers of axons counted on these sections are presented in Figure 6.

TOTAL NUMBER OF AXONS IN PREGANGLONIC TRUNK

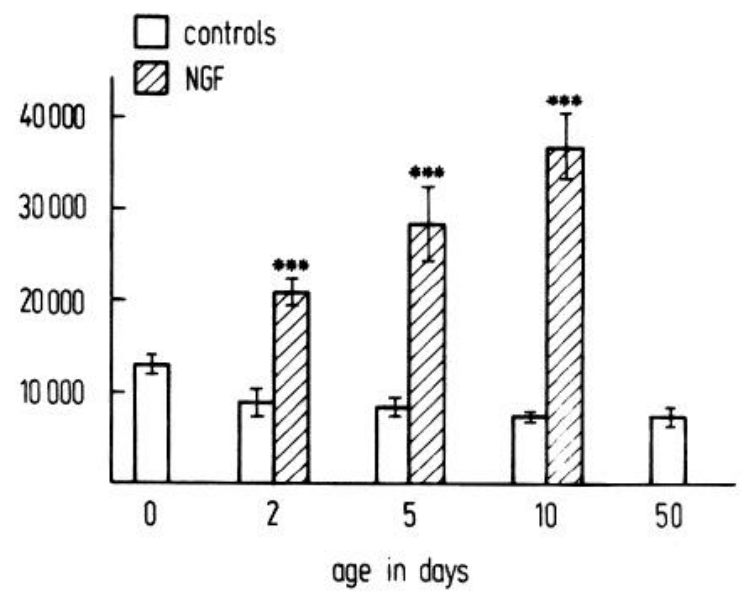

Figure 6. Time course of the increase in the total number of axons present in the rat CST under the influence of NGF. The number of axons was estimated as indicated under "Materials and Methods." The results are expressed as the mean \pm SEM. ${ }^{* * *}, p<0.001$. by retrograde axonal transport in the postsynaptic neurons (Stöckel et al., 1975) and is not transferred to the preganglionic endings terminating on these neurons, in contrast to tetanus toxin (Schwab and Thoenen, 1977; Schwab et al., 1979). Evidence for a direct effect of NGF or for the presence of receptors for NGF on preganglionic neurons has not been found so far. One therefore has to assume an indirect mechanism; e.g., increased production of a "factor" regulating synapse formation by the adrenergic neurons under the influence of NGF. Such a regulatory molecule could be soluble or a membrane constituent. Since only about $1 \%$ of the neuronal surface in the SCG is covered by synapses (Yokota and Yamauchi, 1974), membrane-bound "synaptogenic signals" must be more specific than just the availability of space. It is most significant that such a retrograde transneuronal signal or factor which is under the control of NGF has already been postulated for the maintenance of adult SCG synapses. Postganglionic axotomy or blockade of axonal transport not only has pronounced effects on the corresponding cell bodies in the SCG but leads also to a disconnection of the preganglionic input by synapse re- 

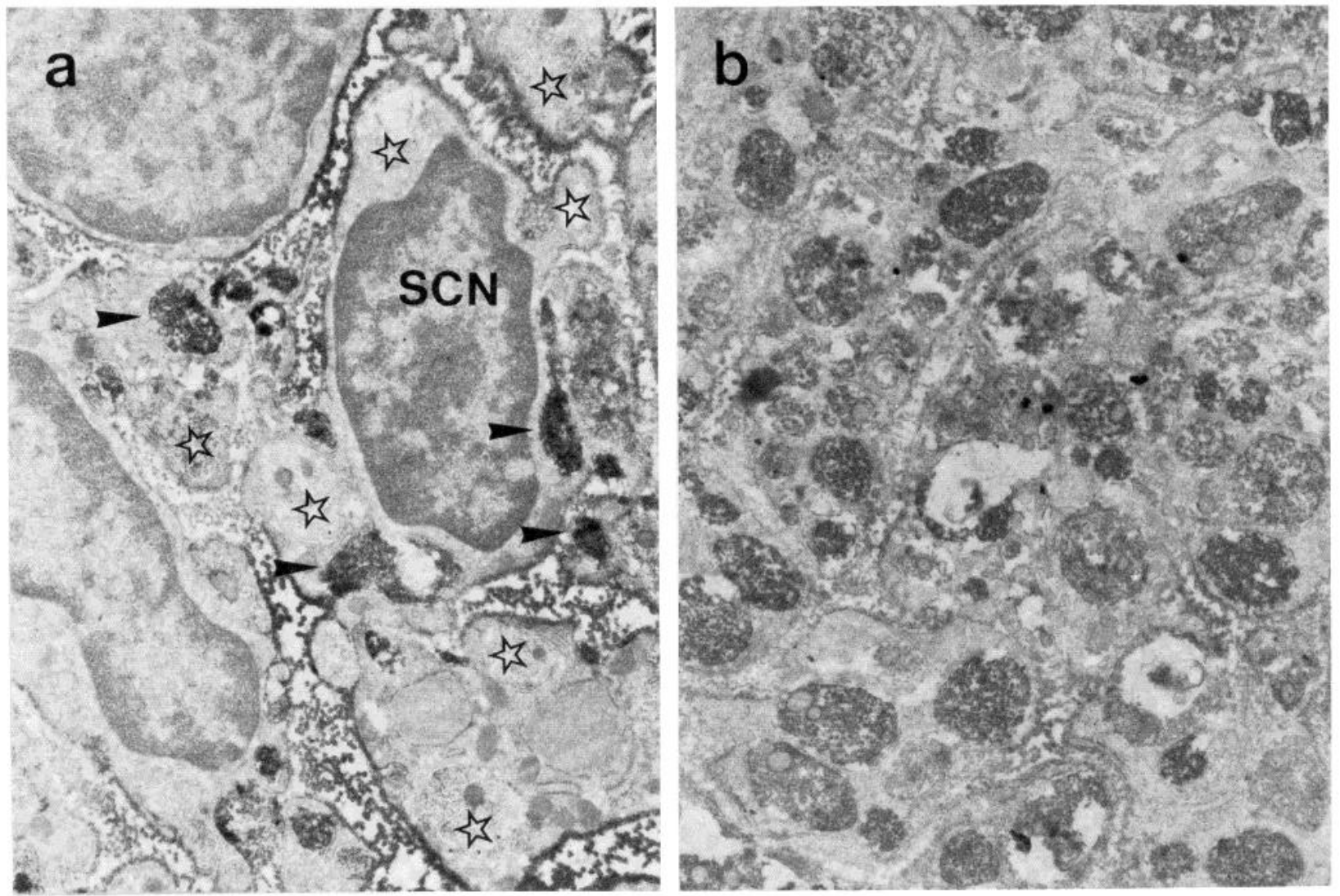

Figure 7. Cross-sections through $(a)$ the preganglionic CST and $(b)$ the postganglionic trunk of a 10-day-old NGF-treated rat. The immunohistochemical labeling with peroxidase was performed with an antiserum against TH as described under "Materials and Methods." The CST of the NGF-treated animal contains labeled adrenergic axons (arrowheads) as well as unlabeled, presumably cholinergic axons (stars). In contrast to the CST, all of the axons are labeled in the adrenergic postganglionic trunk, which serves as a positive control for the immunohistochemical procedure. Magnification $\times 15,000$. SCN, Schwann cell nucleus.

traction (Matthews and Nelson, 1975; Purves, 1975, 1976). These effects are counteracted by NGF and mimicked by anti-NGF antiserum (Njå and Purves, 1978).

The transneuronal effects of NGF were not restricted to the terminal parts of the preganglionic fibers. After 10 days of NGF treatment, the number of cholinergic axons in the CST was increased from 6,000 in controls to 20,000 in treated animals, in regions of the CST close to, and more distant from, the SCG. It has to be pointed out, however, that the axonal population of the CST is not purely cholinergic. In agreement with Brooks-Fournier and Coggeshall (1981), who found $11 \%$ of the CST axons to be postganglionic on the basis of selective lesions in adult rats, immunohistochemical localization of TH as a marker for adrenergic axons showed that around 20\% (about 1,500 axons) of the CST axons were adrenergic in 10-day-old control animals, and that this proportion was increased to $45 \%$ (about 17,000 axons) by the NGF treatment. Since NGF elicits fiber outgrowth from adrenergic neurons by a direct action (Thoenen and Barde, 1980), this increased adrenergic contribution was not unexpected.

Preliminary experiments using retrogradely transported HRP for identification of neurons projecting axons into the CST showed that the proportion of labeled adrenergic SCG and stellate neurons was unchanged in NGF-treated animals. This suggests that the large in- crease in the number of adrenergic axons in the CST is due to collateral sprouting. Although all SCG and stellate neurons probably sprout in response to NGF, no "misrouting" into the CST seems to occur.

Having found a marked positive effect of NGF on the number of cholinergic synapses and preganglionic axons, the determination of the number and location of their cells of origin in the spinal cord would be of great interest. Our preliminary results showed labeled preganglionic sympathetic neurons located in the spinal cord segments C8 to T6, a distribution identical to that found in adult rats (Rando et al., 1981), as well as in adult guinea pigs (Njå and Purves, 1977; Dalsgaard and Elfvin, 1979; Rubin and Purves, 1980) and in newborn and adult hamsters (Lichtman and Purves, 1980). Whereas this rostrocaudal distribution was not affected by 10 days of NGF treatment, the number of labeled spinal cord neurons increased about 1.5-fold. This increased number of labeled cell bodies could result from an increased branching and projection to the SCG, or, alternatively, from an increased survival of young neurons due to an alteration in their target structure (the SCG). In fact, in the 8- to 10day-old chick embryo the prevention of naturally occurring cell death in the preganglionic sympathetic column of the spinal cord by NGF has recently been demonstrated (Oppenheim et al., 1982). Developmental overproduction of neurons and a subsequent reduction to 
match the available target organ(s) constitute a widespread phenomenon in the developing nervous system (for review see Oppenheim, 1981); this phenomenon has also been described for motoneurons in the spinal cord of postnatal rats (Nurcombe et al., 1981; Rootman et al., 1981). However, no data are available concerning the occurrence and time course of these events for preganglionic sympathetic neurons in the rat.

In addition to survival of cholinergic preganglionic nerve cells themselves, the NGF treatment could affect the maintenance of axonal branches or even induce sprouting by the changes in the adrenergic target neurons. Electrophysiological data in the hamster SCG (Lichtman and Purves, 1980) as well as in the rat subInandibular (Lichtman, 1980) and rabbit ciliary ganglion (Johnson and Purves, 1981) gave evidence for a pronounced rearrangement of the preganglionic-postganglionic synaptic connections during development: in particular, a reduction of the number of preganglionic axons contacting a given ganglion cell. NGF-induced changes in the postganglionic neurons stabilizing early transitory connections could thus make an important contribution to the phenomena observed in the present study.

Our results show that the changes produced by NGF in the postganglionic adrenergic neurons of the SCG trigger a series of changes in the input system to these neurons: more cholinergic synapses are formed, and more preganglionic axons project to the SCG. Whether NGF causes an increased availability of synaptic sites, which then leads to a stabilization of axonal sprouts and/or survival of preganglionic neurons, or whether synapse formation and axon number are regulated independently by soluble or membrane-bound factors produced by the NGF-responsive SCG neurons, remains an open question.

\section{References}

Adams, J. C. (1980) Stabilizing and rapid thionin staining of TMB-based HRP reaction product. Neurosci. Lett. 17: 7-9.

Adams, J. C. (1981) Heavy metal intensification of DAB-based HRP reaction product. J. Histochem. Cytochem. 29: 775.

Aguayo, A. J., L. C. Terry, and G. M. Bray (1973) Spontaneous loss of axons in sympathetic unmyelinated nerve fibers of the rat during development. Brain Res. 54: 360-364.

Aguayo, A. J., J. M. Peyronnard, L. C. Terry, J. S. Romine, and G. M. Bray (1976) Neonatal neuronal loss in rat superior cervical ganglia: Retrograde effects on developing preganglionic axons and Schwann cells. J. Neurocytol. 5: 137-155.

Berod, A., B. K. Hartman, and J. F. Pujol (1981) Importance of fixation in immunohistochemistry. J. Histochem. Cytochem. 29: $844-850$.

Black, I. B. (1978) Regulation of autonomic development. Annu. Rev. Neurosci. 1: 183-214.

Black, I. B., I. A. Hendry, and L. L. Iversen (1971) Transsynaptic regulation of growth and development of adrenergic neurons in a mouse sympathetic ganglion. Brain Res. 34: 229240.

Black, I. B., I. A. Hendry, and L. L. Iversen (1972) The role of post-synaptic neurons in the biochemical maturation of presynaptic cholinergic nerve terminals in a mouse sympathetic ganglion. J. Physiol. (Lond.) 221: 149-159.

Bocchini, V., and P. U. Angeletti (1969) The nerve growth factor: Purification as a 30,000-molecular-weight protein. Proc. Natl. Acad. Sci. U. S. A. 64: 787-794.

Bowers, C. W., and R. E. Zigmond (1979) Localization of neurons in the rat superior cervical ganglion that project into different post-ganglionic trunks. J. Comp. Neurol. 185: 381392.

Bowers, C. W., and R. E. Zigmond (1981) Sympathetic neurons in lower cervical ganglia send axons through the superior cervical ganglion. Neuroscience 6: 1783-1791.

Brooks-Fournier, R., and R. E. Coggeshall (1981) The ratio of preganglionic axons to postganglionic cells in the sympathetic nervous system of the rat. J. Comp. Neurol. 197: 207-216.

Dalsgaard, C. J., and L. G. Elfvin (1979) Spinal origin of preganglionic fibers projecting onto the superior cervical ganglion and inferior mesenteric ganglion of the guinea pig, as demonstrated by the horseradish peroxidase technique. Brain Res. 172: 139-143.

Eränkö, L. (1972) Ultrastructure of the developing sympathetic nerve cell and the storage of catecholamines. Brain Res. 46: 159-175.

Fonnum, F. (1975) A rapid radiochemical method for the determination of choline acetyltransferase. J. Neurochem. 24: 407-409.

Griffin, G., L. R. Watkins, and D. J. Mayer (1979) HRP pellets and slow-release gels: Two new techniques for greater localization and sensibility. Brain Res. 168: 595-601.

Grinnell, A. D., and A. A. Herrera (1981) Specificity and plasticity of neuromuscular connections: Long-term regulation of motoneuron function. Prog. Neurobiol. 17: 203-282.

Hendry, I. A., and J. Campbell (1976) Morphometric analysis of rat superior ganglion after axotomy and nerve growth factor treatment. J. Neurocytol. 5: 351-360.

Hill, C. E., and I. A. Hendry (1977) Development of neurons synthesizing noradrenaline and acetylcholine in the superior cervical ganglion of the rat in vivo and in vitro. Neuroscience 2: 741-749.

Johnson, D. A., and D. Purves (1981) Post-natal reduction of neural unit size in the rabbit ciliary ganglion. J. Physiol. (Lond.) 318: 141-159.

Johnson, E. M., M. T. Caserta, and L. L. Ross (1977) Effects of destruction of the postganglionic sympathetic neurons in neonatal rats on development of choline acetyltransferase and survival of preganglionic cholinergic neurons. Brain Res. 136: 455-464.

Kondo, H., N. J. Dun, and G. D. Pappas (1980) A light and electron microscopic study of the rat superior cervical ganglion cells by intracellular HRP-labeling. Brain Res. 197: 193-199.

Landmesser, L. T. (1980) The generation of neuromuscular specificity. Annu. Rev. Neurosci. 3: 279-302.

Landmesser, L. T., and G. Pilar (1978) Interactions between neurons and their targets during in vivo synaptogenesis. Fed. Proc. 37: 2016-2022.

Levitt, M., J. W. Gibb, J. Daly, M. Lipton, and S. Udenfriend (1967) A new class of tyrosine hydroxylase inhibitors and a simple assay of inhibition in vivo. Biochem. Pharmacol. 16: 1313-1321.

Lichtman, J. W. (1980) On the predominantly single innervation of submandibular ganglion cells in the rat. J. Physiol. (Lond.) 302: 121-130.

Lichtman, J. W., and D. Purves (1980) The elimination of redundant preganglionic innervation to the hamster superior cervical ganglion in early post-natal life. J. Physiol. (Lond.) 301: 213-228.

Lowry, O. H., N. J. Rosebrough, A. L. Farr, and R. J. Randall (1951) Protein measurement with the Folin phenol reagent. J. Biol. Chem. 193: 265-275.

Matthews, M. R., and V. H. Nelson (1975) Detachment of structurally intact nerve endings from chromatolytic neurones of rat superior cervical ganglion during the depression of synaptic transmission induced by postganglionic axotomy. J. Physiol. (Lond.) 245: 91-135.

Mesulam, M. M. (1978) Tetramethyl benzidine for horseradish 
peroxidase neurohistochemistry: A non-carcinogenic blue reaction-product with superior sensitivity for visualizing neural afferents and efferents. J. Histochem. Cytochem. 26: 106-117.

Mueller, R. A., H. Thoenen, and J. Axelrod (1969) Increase in tyrosine hydroxylase activity after reserpine administration. J. Pharmacol. Exp. Ther. 169: 74-79.

Njå, A., and D. Purves (1977) Specific innervation of guinea-pig superior cervical ganglion cells by preganglionic fibres arising from different levels of the spinal cord. J. Physiol. (Lond.) 264: 565-583.

$\mathrm{Njå}, \mathrm{A}$., and D. Purves (1978) The effects of nerve growth factor and its antiserum on synapses in the superior cervical ganglion of the guinea pig. J. Physiol. (Lond.) 277: 53-75.

Nurcombe, B., P. A. McGrath, and M. R. Bennett (1981) Postnatal death of motor neurons during the development of the brachial spinal cord of the rat. Neurosci. Lett. 27: 249254.

Oppenheim, R. W. (1981) Neuronal cell death and some related regressive phenomena during neurogenesis: A selective historical review and progress report. In Studies in Developmental Neurobiology, W. M. Cowan, ed., pp. 74-133, Oxford University Press, New York.

Oppenheim, R. W., J. L. Maderdrut, and D. J. Wells (1982) Cell death of motoneurons in the chick embryo spinal cord VI. Reduction of naturally occurring cell death in the thoracolumbar column of Terni by nerve growth factor. J. Comp. Neurol. 210: 174-189.

Pannese, E., R. Bianchi, B. Calligaris, R. Ventura, and E. R. Weibel (1972) Quantitative relationships between nerve and satellite cells in spinal ganglia. An electron microscopical study. I. Mammals. Brain Res. 46: 215-234.

Purves, D. (1975) Functional and structural changes in mammalian sympathetic neurones following interruption of their axons. J. Physiol. (Lond.) 252: 429-463.

Purves, D. (1976) Functional and structural changes in mammalian sympathetic neurones following colchicine application to post-ganglionic nerves. J. Physiol. (Lond.) 259: 159-175.

Purves, D., and R. I. Hume (1981) The relation of postsynaptic geometry to the number of presynaptic axons that innervate autonomic ganglion cells. J. Neurosci. 1: 441-452.

Rando, T. A., C. W. Bowers, and R. E. Zigmond (1981) Localization of neurons in the rat spinal cord which project to the superior cervical ganglion. J. Comp. Neurol. 196: 73-83.

Rootman, D. S., W. G. Tatton, and M. Hay (1981) Postnatal histogenetic death of rat forelimb motoneurons. J. Comp. Neurol. 199: 17-27.

Rubin, E., and D. Purves (1980) Segmental organization of sympathetic preganglionic neurons in the mammalian spinal cord. J. Comp. Neurol. 192: 163-174.

Saunders, N. R., K. Dziegielweska, C. H. Häggendal, and A. B.
Dahlström (1973) Slow accumulation of choline acetyltransferase in crushed sciatic nerves of the rat. J. Neurobiol. 4: 95-103.

Schwab, M. E., and H. Thoenen (1977) Selective trans-synaptic migration of tetanus toxin after retrograde axonal transport in peripheral sympathetic nerves: A comparison with nerve growth factor. Brain Res. 122: 459-474.

Schwab, M. E., K. Suda, and H. Thoenen (1979) Selective retrograde transsynaptic transfer of a protein, tetanus toxin, subsequent to its retrograde axonal transport. J. Cell Biol. 82: 798-810.

Smolen, A., and G. Raisman (1980) Synapse formation in the rat superior cervical ganglion during normal development and after neonatal deafferentiation. Brain Res. 181: 315-323.

Stöckel, K., M. Schwab, and H. Thoenen (1975) Comparison between the retrograde axonal transport of nerve growth factor and tetanus toxin in motor, sensory and adrenergic neurons. Brain Res. 99: 1-16.

Suda, K., Y. A. Barde, and H. Thoenen (1978) Nerve growth factor in mouse and rat serum: Correlation between bioassay and radioimmunoassay determinations. Proc. Natl. Acad. Sci. U. S. A. 75: 4042-4046.

Thibault, J., D. Vidal, and F. Gros (1981) In vitro translation of InRNA from rat phenochromocytoma tumors, characterization of tyrosine hydroxylase. Biochem. Biophys. Res. Commun. 99: 960-968.

Thoenen, H., and Y. -A. Barde (1980) Physiology of nerve growth factor. Physiol. Rev. 60: 1284-1335.

Thoenen, H., P. U. Angeletti, R. Levi-Montalcini, and R. Kettler (1971) Selective induction of tyrosine hydroxylase and dopamine $\beta$-hydroxylase in rat superior cervical ganglia by nerve growth factor. Proc. Natl. Acad. Sci. U. S. A. 68: 15981602.

Thoenen, H., A. Sancr, P. U. Angeletti, and R. Levi-Montalcini (1972) Increased activity of choline acetyltransferase in sympathetic cervical ganglia after prolonged administration of nerve growth factor. Nature New Biol. 236: 26-28.

Thoenen, H., U. Otten, and M. Schwab (1979) Orthograde and retrograde signals for the regulation of neuronal gene expression: The peripheral sympathetic nervous system as a model In The Neurosciences: Fourth Study Program, F. O. Schmitt and F. E. Worden, eds., pp. 911-928, MIT Press, Cambridge, MA.

Wooten, G. F., and J. T. Coyle (1973) Axonal transport of catecholamine synthesizing and metabolizing enzymes. J. Neurochem. 20: 1361-1371.

Yokota, R., and A. Yamauchi (1974) Ultrastructure of the mouse superior cervical ganglion with particular reference to the pre- and post-ganglionic elements covering the soma of its principal neurons. Am. J. Anat. 140: 281-298. 